\title{
Angels in the architecture - and devils in the detail: how the learning space impacts on teaching and learning
}

Jane Challinor

Nottingham Trent University

\begin{abstract}
An innovative classroom design, pioneered in the US and aiming to facilitate greater student engagement, has been piloted in a UK University. This case study reflects on some of the advantages and the challenges of this technology-rich learning space and considers its impact on curriculum design in a module which aims to develop academic, research and digital skills in first-year students on an undergraduate Health and Social Care course.
\end{abstract}

\section{Introduction}

The 'SCALE UP' (See: http://scaleup.ncsu.edu/ ) approach to large-group, enquiry-based teaching was developed in North Carolina State University by Professor Robert Beichner, to improve student engagement and attainment. According to Beichner (2008), the original meaning of the acronym was 'Student Centred Activities for Large Enrolment Undergraduate Physics'; it now signifies 'Student Centred Active Learning Environment with Upside-down Pedagogies'. 'Upside-down Pedagogies' refers to a 'flipped classroom' approach (originally termed 'the inverted classroom' by Lage, Platt and Treglia, 2000), with classes typically consisting of group activities and investigations to aid understanding of theory.

SCALE UP was envisaged as the solution to the 'problem' of the changing nature of higher education and what was expected of it. Students, according to Beichner (2014), were not enjoying learning and employers required different skills from graduates. The traditional lecture was no longer seen as appropriate for the teaching of STEM subjects in particular.

Mann and Robinson (2009) found that UK students in higher education also tended to view lectures as boring, resulting in poor attendance and lower grade averages, whilst Beetham (2014) has pointed out that the use of technologies in higher education can enable students to make the transition to academic ways of thinking, especially if they meet these in a relatively familiar space.

The idea of active learning derives from a more student-centred learning paradigm which has been developing in education over many years - a paradigm which has at its heart ideas about innovative teaching, working in teams and problem-based learning (Attard, 2010). As Davidson (2011) points out, traditional classroom environments were designed during the industrial age to produce factory hands; in the age of the Internet, a different pedagogy and a different learning space are required.

Since its introduction in the US, SCALE UP has been adopted in a number of countries around the world, including Australia, the UK, the United Arab Emirates and Denmark, and in disciplines as diverse as humanities, sports education, law and social work (Nottingham Trent University, 2014). 
This case study reports on the author's personal experience of being one of thirty module leaders piloting the SCALE UP approach at Nottingham Trent University (NTU) during 2013/14.

\section{The physical and pedagogical underpinnings of SCALE UP}

Technology

The SCALE UP classroom environment is physically different from that normally used for large groups of students. In the US, SCALE UP classrooms are on one level and typically accommodate around 100 students, seated in groups of nine at large round tables. The environment is technology-rich, with laptops, multiple wall-mounted screens, Apple TV and wi-fi connection to the Internet.

The layout of the classroom and the shape of the tables not only support, but perhaps actually dictate, a very different style of teaching and learning, as the students are mostly facing away from the tutor and towards one another. Group collaboration is therefore facilitated by this design, whilst traditional 'lecturing' is actively discouraged. Beichner (2006) has said that, arguably, the most important technology in the SCALE UP room is the table.

Group work

In Professor Beichner's 'classic' SCALE UP model, tables are sub-divided into three groups of three students each. By means of regular testing, these groups are pre-selected with a mix of higher-, middle- and lower-ability students; the aim is that the higher-ability students assist those with lower-level skills to achieve better grades. Group members are given specific tasks - for example, one records activities and findings, one carries out the experiment or task and the third questions assumptions and challenges findings to arrive at a more rigorously-tested answer (Beichner, 2008).

Support for staff

Adapting to a different teaching style and to SCALE UP's physical environment, managing large numbers of students and coping with both high noise levels and the challenges that are an inevitable part of working with technology all make huge demands on teaching staff. In one adaptation of SCALE UP in the US, the TILE model at the University of lowa, academic staff are required to undergo a three-day intensive training known as the TILE Institute. They are also provided with continuing support, both in converting conventional classes to student-centred, active ones and in using instructional technologies and specific software (Gaffney, Horne, Jesse and Murniaiti, 2012).

\section{Implementation of SCALE UP in a first-year study skills module}

\section{Physical environment}

This case study is based on a first-year study skills module involving 103 undergraduate Health and Social Care students. In many ways, the problems faced in the module were similar to those outlined by Professor Beichner. The aim of the module had originally been to teach basic research skills and academic conventions, but poor attendance indicated that 
students did not find it engaging. Additionally, the course team felt that the content was not addressing the twenty-first century skills (Blinkley et al, 2011) demanded by employers.

Over the previous three years, the introduction of selected Web 2.0 tools (such as social bookmarking) and an increasing emphasis on group work had shifted the focus of the module towards the development of these new skills (in particular, collaborative problemsolving and digital skills), but resources to support this approach were limited: to familiarise students with specific web-based tools, staff were obliged to use a small, twenty-seat IT suite with fixed PCs set out in rows, one machine per student, and this meant repeating the session five times to deal with the entire cohort; a traditional seminar room was similarly restrictive, as they had to manage group work by re-arranging tables to enable students to face each other.

The SCALE UP classroom model appeared to offer the ideal solution. Participation in the pilot made it possible to integrate a range of digital tools seamlessly into every session, whilst offering the physical environment needed for effective group interaction within a large class setting.

However, there were some challenges. In the 'pure' form of SCALE UP, the teacher's station is in the centre of the room and tables are seven feet in diameter. Gaffney, Horne, Jesse and Murniaiti (2012) highlight that a smaller table makes students feel cramped, whilst a larger one is detrimental to group discussions. In the pilot at NTU, there were twelve tables which were six feet three inches in diameter and students did indeed complain about feeling cramped; likewise, since the room provided was also rather smaller than those in some US models, the tutor found it difficult to move around to support the groups.

\section{Group work}

Beichner (2008) advocates carefully-structured groups of mixed abilities in order to facilitate 'cooperative learning'. As defined by Johnson (1991, page 5):

"Cooperative learning is the instructional use of small groups so that students work together to maximise their own and each other's learning."

Working in cooperative groups is the norm in the majority of modules on the Health and Social Care course - a deliberate course-design decision which helps prepare students for team-working in their future employment. In the study skills module, however, the usual practice is not to engineer mixed-ability groups, but to allow students to form groups of their own choosing. This practice has tended to overcome any initial resistance to group work, particularly if groups are formed after ice-breaking activities for students to get to know one another.

One disadvantage of self-selection, however, is that students who may be rather disengaged or on the periphery of the cohort may not easily find a group where they fit and so become demotivated or further disengaged. Groups also tend to be homogenous - lower-ability students may stick together and do worse in assessments, as they do not have the benefit of learning from the more able students (Collins and Goyder, 2008).

Groups may also form from similarities in culture, race and age (Arkoudis et al, 2010). In the study skills module, for example, one group which came together because of strong 
friendship ties was formed entirely of students with English as an additional or second language. They attended well and appeared always to be on task, rarely asking for support. However, they achieved the lowest marks of any group in the final project because (as became apparent during a feedback discussion with the tutor) they had understood neither the task nor the assessment criteria.

Given the diverse cultural backgrounds of the module cohort as a whole - and especially the large proportion of mature students - some deliberate strategy to structure groups may well be advisable in future, although as Boud, Cohen and Sampson (1999) note, there are still considerable difficulties in trying to manage groups composed of individuals of different ages, life experiences and cultures who are not used to working together in this way.

Students going 'off task' is another often-reported problem of the SCALE UP type of learning space (Brooks, 2012), owing mainly to unsupervised access to the Internet during group activities. In the study skills module, the most frequent distractions observed involved answering emails, checking Facebook, viewing websites on non-educational topics and completing work for other modules. To have established at the outset a clearly-defined purpose might well have produced greater group cohesion, focus and commitment, since, in term two, students were noticeably less distracted once formed into fixed project groups with a research task to complete for the module's summative assessment.

\section{Evaluation}

Student satisfaction and digital skills

Despite some problems, as outlined above, group work was rated positively by the majority and was specifically mentioned by many as a valuable feature of the module. In an online survey conducted in December 2013 (at the end of term one) about their experience of the module so far, $56 \%$ of students who responded (total responses $=53$ ) reported enjoying the group-based activities.

Other positive features of the evaluation included $60 \%$ reporting that they had learned new ICT skills and $74 \%$ confirming good levels of tutor support in class. Students were, however, generally not satisfied with the delivery of the seminars in the SCALE UP environment. For example, $58 \%$ felt that the classes were not well-organised and $96 \%$ thought the class size too big. Student feedback also referred to a sense of overcrowding in the room, slow response by teachers when support was required, high noise levels and a lack of familiarity with the technology (all issues highlighted by the University of Minnesota, 2011, in its guidance for instructors in the use of 'Active Learning Classrooms').

A formal course evaluation of the module was carried out through the normal Module Evaluation Questionnaire method towards the end of term two (March 2014). This time, 75\% of students responding (total responses $=48$ ) said that the module was well-organised and $70 \%$ felt they understood how it linked with the rest of their course. This might suggest that, unlike their initial experience, their now greater familiarity with the module's approach enabled them to see it as purposeful and relevant to their learning. However, overall levels of satisfaction and attendance on the module did not show any significant improvement on previous years. 
A sample of typical written comments from students is given below:

What aspects of the module have you enjoyed overall?

"learning how to carry out research"

"Each task is relevant to Health and Social Care and often learn new skills for the future e.g referencing."

"its amazing what we can find for ourselves with a pc or a laptop"

"group work activities; using the computers; referencing"

"it's very different from the other modules, gives you a chance to expand on researching skills"

What could be improved (about the module overall)?

"it is good but the layout of the room makes it difficult to hear everything"

"more time for the tasks"

"classes too big, too vague, I don't feel like I am coming away having learnt anything"

"hard to ask questions as it's a big group"

In the December survey, students were also asked about their digital skills, enabling a comparison to be made between these responses and those given in response to the same survey sent out to students in a pre-induction activity. The responses reveal that students' familiarity with certain online tools had increased - notably, Google Scholar, Evernote and Linkedln. They also reported that their levels of confidence in searching for, referencing and storing information had increased - for example, through the use of library databases and mobile bookmarking tools.

Based on the author's experience and the students' evaluation of the pilot, improvements to the structure of the module have subsequently been implemented: longer (two-hour) workshops with fewer students (achieved by splitting the cohort into two) have been timetabled and a portfolio-based assessment has been introduced, encouraging students to work collaboratively on a range of innovative digital projects during the weekly seminars. These measures appear to be having a positive impact on attendance and engagement.

Impact on curriculum design

Using the SAMR (Substitution, Augmentation, Modification and Redefinition) model of technology adoption in curriculum design (Puentedura, 2014), it is possible to analyse the extent to which the technology involved in the SCALE UP pilot, together with the room design and table layout, impacted on teaching and learning activities.

In the majority of cases, the learning activities used were the same as, or similar to, those of previous years, but the Scale Up classroom encouraged innovation:

For 'Substitution', students created a shared Word document or PowerPoint slide, instead of a paper-based worksheet, to report group discussions. For

'Augmentation', in which the technology adds functional improvement (in this instance on a whiteboard or flipchart), they used Padlet (www.padlet.com - a virtual 'wall' on which students can post comments) and were overwhelmingly positive about it, noting in particular that it enabled less confident students to make contributions to idea-sharing activities; the Padlet wall also permitted students to share videos, images and weblinks and served as a permanent revision resource for the class. 
'Modification' involved a literature search task, for which, in 2011/2012, prior to SCALE UP, students had been given an IT suite demonstration of how to use the library databases, before they conducted an online search for journal articles using key words which they saved in a Word document or email; however, in the peer-topeer, resource-sharing, live-document-editing environment of the 2013/2014 SCALE UP classroom, they collaborated in groups of three to search for journal articles, before copying links to their found sources into a shared Google Drive document for everyone to use in a range of course assignments - and their comments certainly do testify to their appreciation of the opportunity to complete tasks in groups!

'Redefinition' may be exemplified by the 2013/2014 live collaboration of over 100 students, simultaneously creating and editing a slideshow on Google Drive as a way of developing familiarity with both online collaboration methods and cloud storage tools; whilst this might have been technically possible outside SCALE UP, such challenges as lack of laptops and of spaces suitable for group work on such a scale meant that it had never previously been considered - the new space effectively shaped ideas about new ways of delivering the curriculum.

\section{Final considerations}

In the many US-based evaluations of the SCALE UP approach, mostly positive outcomes have been noted - especially improved attendance and grade averages. There are, however, some issues highlighted as potential drawbacks:

Using a space such as the SCALE UP classroom with traditional teacher-centred delivery methods (lecturing) seems, according to Lasry et al, 2013, to produce worse than usual results. This may be because the round tables, the very design element which facilitates group work and collaborative learning, cause many students to be facing away from the lecturer. For this reason, the NTU timetable for the SCALE UP classroom gives priority to those modules employing a collaborative, student-centred approach rather than to those based on traditional pedagogies. Plans are in place to extend the number of SCALE UP classrooms available at NTU as demand for the existing space has outstripped capacity. To support this, staff development initiatives that include both classroom training sessions and a VLE-based community (featuring videos of pilot leaders sharing their experiences) have been introduced.

Another evaluation from Massachusetts Institute of Technology (MIT) warned that students may respond less positively to the SCALE UP approach if the rest of their modules are delivered in a more traditional manner (Dory and Belcher, 2005). This may explain students' negative responses to the module during the pilot. As more modules have been delivered in this space, the task of overcoming student resistance has diminished. Evidence of this is apparent in the second iteration of SCALE UP at NTU, with students who experienced the pilot manifestly more comfortable with the technology and the learning space from the outset of the academic year and attendance showing a marked improvement.

What this pilot indicates is that the basic concept of SCALE UP has the potential genuinely to redefine approaches to teaching and learning. If rows of desks facing the blackboard 
shaped educational practices in the past (Davidson 2011), a range of innovative learning spaces - a new learning architecture - will need to continue to be explored in order to support the development of skills for the twenty-first century. When it comes to supporting students and educators - to embrace these new spaces, getting the details right could make all the difference.

\section{Reference list}

Arkoudis, S., Yu, X., Baik, C., Borland, H., Chang,S., Lang,I., Lang,J., Pearce, A., Watty,K. (2010) 'Finding Common Ground: enhancing interaction between domestic and international students.' In: Report of project supported by the Australian Learning and Teaching Council $L t d$, an initiative of the Australian Government Department of Education, Employment and Workplace Relations. Available at:

http://www.cshe.unimelb.edu.au/research/projectsites/enhancing_interact.html (Accessed: 27 July 2014).

Attard, A. (ed) (2010) 'Student Centered Learning: An Insight Into Theory And Practice.' European Students Union. Available at: http://www.esuonline.org/pageassets/projects/projectarchive/2010-T4SCL-Stakeholders-Forum-Leuven-AnInsight-Into-Theory-And-Practice.pdf (Accessed: 1 February 2015).

Beetham, H., (2014) 'Editorial.' Journal of Learning Development in Higher Education Special Edition: Digital Technologies, November 2014,1-8.

Beichner, R.J. (2006) 'North Carolina State University: Scale Up'. In: Oblinger, D.G.(ed) Learning Spaces, Educause. Available at: http://www.educause.edu/research-andpublications/books/learning-spaces/chapter-29-north-carolina-state-university-scale (Accessed: 6 September 2014).

Beichner, R. J (2008) 'The SCALE-UP Project: A Student-Centered, Active Learning Environment for Undergraduate Programs.' National Academy of Sciences White Paper. Available at: www.nationalacademies.org/bose/Beichner_CommissionedPaper.pdf (Accessed: 26 July 2014).

Beichner, R.J.(2014) 'History and Evolution of Active Learning Spaces.' New Directions for Teaching and Learning Volume 2014, Issue 137 Spring 2014, 9-16. Available at: http://onlinelibrary.wiley.com/doi/10.1002/tl.2014.2014.issue-137/issuetoc. (Accessed: 5 September 2014).

Binkley, M., Erstad, O., Herman,J., Raizen,S., Ripley, M., Miller-Ricci, M., Rumble, M. (2011) 'Defining Twenty-First Century Skills.' In: Griffin,P., McCaw, B. and Care,E. (eds.) Teaching and Assessing $21^{\text {st }}$ Century Skills. Springer, Melbourne.

Boud, D.; Cohen,R.;Sampson, J. (1999) 'Peer Learning and Assessment.' Assessment \& Evaluation in Higher Education, 24 (4), 413-426 Available at: http://citeseerx.ist.psu.edu/viewdoc/download?doi=10.1.1.203.1370\&rep=rep1\&type=pdf (Accessed: 4 September 2104).

Brooks, D.C. (2012) 'Space and Consequences: The Impact of Different Formal Learning Spaces on Instructor and Student Behavior.' Journal of Learning Spaces, 1 (2), University of Minnesota. Available at: http://libjournal.uncg.edu/index.php/jls/article/view/285/275 (Accessed: 6 September 2014). 
Collins, N., Goyder, J. (2008) 'Speed Dating: a Process of Forming Undergraduate Student Groups.' In: ECulture Vol.1 Available at:

http://ro.ecu.edu.au/cgi/viewcontent.cgi?article=1075\&context=eculture (Accessed: 6 September 2014).

Davidson, C.N., (2011) Now You See It: How Technology and Brain Science Will Transform Schools and Business for the 21st Century. New York: Penguin.

Dori,Y.J. and Belcher,J. (2005) 'How Does Technology-Enabled Active Learning Affect Undergraduate Students' Understanding of Electromagnetism Concepts?' The Journal of the Learning Sciences 14 (2), 243-279. Available at:

http://web.mit.edu/edtech/casestudies/pdf/teal1.pdf (Accessed: 1 February 2015).

Johnson, David W. (1991) 'Cooperative Learning: Increasing College Faculty Instructional Productivity.' In: ASHE-ERIC Higher Education Report No. 4. Available at: http://files.eric.ed.gov/fulltext/ED343465.pdf (Accessed: 5 September 2014).

Lage, M. J., Platt, G. J., Treglia, M.(2000) 'Inverting the Classroom: A Gateway to Creating an Inclusive Learning Environment.' The Journal of Economic Education, 31 (1) (Winter, 2000), 30-43.

Lasry, N., Charles, E., Whittaker, C., Dedic, H., Rosenfield, S. (2013) 'Changing Classroom Designs: Easy; Changing Instructors' Pedagogies: Not So Easy...' In: AIP Conference Proceedings; Jan 2013, 1513 (1), 238 Available at:

http://connection.ebscohost.com/c/articles/85040222/changing-classroom-designs-easychanging-instructors-pedagogies-not-so-easy (Accessed: 1 February 2015).

Mann,S., Robinson,A.,(2009) 'Boredom in the lecture theatre: an investigation into the contributors, moderators and outcomes of boredom amongst university students.' British Educational Research Journal, 35 (2), 243-258.

Nottingham Trent University (2014) 'Scale-Up.' Available at: http://www.ntu.ac.uk/adq/teaching/scale_up/index.html (Accessed: 31 January 2015).

Puentedura, R.R. (2014) 'SAMR and Curriculum Design.' In: Ruben R. Puentedura's Weblog (blog) August 29 2014. Available at:

http://www.hippasus.com/rrpweblog/archives/2014/08/30/SAMRAndCurriculumRedesign.pdf (Accessed: 6 September 2014).

University of Minnesota (2011) 'Room Issues in Active Learning Classrooms.' Available at: http://www1.umn.edu/ohr/teachlearn/alc/challenges/roomissues/index.html (Accessed: 6 September 2014).

Van Horne,S., Murniati,C., Gaffney,J.D.H., Jesse,M. (2012) 'Promoting Active Learning in Technology-Infused TILE Classrooms at the University of lowa.' Journal of Learning Spaces 1 (2). Available at: http://libjournal.uncg.edu/index.php/jls/article/view/344/286 (Accessed: 26 July 2014). 